\title{
Complicated intra-abdominal infections: a prospective validation study of the WSES Sepsis Severity Score
}

\author{
Saleh $\underline{\text { Abdel-Kader }}{ }^{1}$, PhD, MRCs, Massimo Sartelli ${ }^{2}$, MD, Fikri M $\underline{\text { Abu-Zidan }}{ }^{3}$, FRCS, PhD
}

INTRODUCTION The World Society of Emergency Surgery (WSES) recently developed and validated a sepsis severity score for complicated intra-abdominal infections (clAls). We aimed to prospectively study the validity of this score in our local setting and compare it with global findings.

METHODS In a prospective study of 100 consecutive adult patients with clAls treated at Al-Ain Hospital, United Arab Emirates, from October 2014 to January 2016, we studied patients' demographics, disease, risk factors, WSES Sepsis Severity Score, management, hospital stay and mortality. Our findings were compared with those from a recent global multicentre prospective study from 53 countries $(n=4,496)$.

RESULTS Compared with global data, our patients were more likely to be male $(p<0.0001)$ and younger $(p<0.0001)$, with more appendicitis and perforated peptic ulcers $(p<0.0001)$, significantly lower sepsis severity score $(p<0.0001)$ and more delays in surgical intervention $(p=0.001)$. Nevertheless, they had similar adequate source control $(p=0.54)$ and surgical reinterventions $(p=0.63)$. Overall, our patients had a significantly lower mortality rate $(1.0 \%$ vs. $9.3 \%$ in global data; $p=0.001)$. A direct logistic regression model showed that the WSES Sepsis Severity Score significantly predicted mortality ( $p<0.0001$ ), but our hospital's setting was not predictive of mortality compared with other hospitals $(p=0.18)$. CONCLUSION Although our patient demographics and hospital's setting significantly differed from those of other international hospitals, the WSES Sepsis Severity Score was very accurate in predicting mortality among our patients, which supports its generalisability for all patient populations worldwide.

Keywords: global, intra-abdominal infection, scoring, sepsis, severity

\section{INTRODUCTION}

Complicated intra-abdominal infections (clAls) are defined as infections that extend beyond organs, causing localised or diffuse peritonitis. ${ }^{(1)}$ They can be serious, with profound morbidity and mortality. Although the mainstay treatment for clAls is source control and appropriate antibiotic therapy, ${ }^{(2)}$ other factors can affect outcome. These include age of patient, severity of sepsis and its extent, organ failure on presentation, type of acquired infection, comorbidities and immunosuppression. ${ }^{(3-5)}$

The World Society of Emergency Surgery (WSES) performed a global prospective observational study on patients with $\mathrm{ClAls}^{(6,7)}$ and has developed a sepsis severity scoring system that could be used worldwide. Another recent WSES global study has validated this score ${ }^{(8)}$ and found it to be highly accurate, easy to compute and practical for patients with clAls.

Important factors to be considered in this context include the local hospital setting, nature of local pathology, standards of healthcare administered, underlying health status of the patient and economic variables. The United Arab Emirates (UAE) is uniquely placed, as it is an extremely rapidly developing highincome country. Swift economic progress has meant that a number of fast-paced commercial projects have come up in a short time, employing and accommodating a large number of young foreign men. ${ }^{(9)}$ People from over 200 countries live in the $U A E,{ }^{(10)}$ thus lending great diversity to the pathologies treated in our hospitals. Given this heterogeneity, we were interested to compare the data from patients with clAls in our hospital setting with the global sepsis data. The present study thus aimed to prospectively assess the validity of the WSES Sepsis Severity Score in our local setting and compare our results with global findings.

\section{METHODS}

Al-Ain Hospital, Al-Ain, UAE, is a major specialised acute care hospital, with 35 specialist departments and a capacity of over 400 beds. ${ }^{(11)}$ The hospital is located in Al-Ain city, which has a population of more than 700,000 at present. ${ }^{(12)}$ The study included all patients who were aged 18 years or over, had clAls, and had undergone interventional drainage or surgery for disease management at our hospital during a 15-month period from October 2014 to January 2016.

Ethical approval for this study was obtained from the Al-Ain Hospital Research and Ethics Governance Committee (ethical approval no. AAH/EC-09-14-014). The study did not affect the routine healthcare provided to our patients and met the standards outlined in the Declaration of Helsinki. All patients who were admitted to Al-Ain Hospital signed a general consent form permitting the use of their anonymous data for audit and research purposes.

Management was considered delayed if patients had localised or diffuse peritonitis for more than 24 hours before intervention. Patients were considered to have healthcare-associated infections if they had been exposed to a healthcare facility (although it may not have been the cause of infection). ${ }^{(13)}$ Immunosuppression

\footnotetext{
${ }^{1}$ Department of Surgery, Al-Ain Hospital, Al-Ain, United Arab Emirates, ${ }^{2}$ Department of Surgery, Macerata Hospital, Italy, ${ }^{3}$ Department of Surgery, College of Medicine and Health Sciences, UAE University, Al-Ain, United Arab Emirates

Correspondence: Prof Fikri M Abu-Zidan, Professor, Department of Surgery, College of Medicine and Health Sciences, UAE University, Al-Ain, United Arab Emirates, fabuzidan@uaeu.ac.ae
} 
included immunosuppressant agents, chemotherapy, chronic glucocorticoids therapy, human immunodeficiency virus and lymphatic disease in the active phase. Severe sepsis and septic shock were defined according to the Surviving Sepsis Campaign guidelines for management of severe sepsis and septic shock. ${ }^{(14}$

Overall, 100 consecutive patients were studied. Data was prospectively collected by the first author on a daily basis. Data collected included patient demographics and disease, source and type of infection, severity of sepsis, associated diseases, delay in management, adequate control of the source of infection, use of empirical antibiotics, need for reintervention, hospital stay and mortality. The WSES Sepsis Severity Score was calculated according to the table shown in the Appendix. ${ }^{(8)}$ Its value ranged between 0 and 18 .

Our data was compared with that of a recent global multicentre prospective observational study by the WSES that studied patients with clAls from 132 medical institutions in 54 countries worldwide. ${ }^{(8)}$ Permission was obtained from the WSES to use crude data from their recently published prospective study ${ }^{(6)}$ for comparison with our local data, in lieu of the global cohort. Data of 36 patients who were enrolled in the WSES study from our hospital was excluded from analysis and that of patients from the other 131 centres in 53 countries was retained for comparison.

Sample size was calculated depending on the number of patients needed to achieve a significant difference in mortality $(p<0.05)$ when compared with the global data $(n=4,500$, mortality $9 \%$ ) using Fisher's exact test. The expected mortality of clAls in our hospital was less than $3 \%$ and the calculated sample size for our study was 95 patients.

Data was entered into a Microsoft Excel 2010 datasheet (Microsoft Corporation, Redmond, WA, USA) and then coded as numbers for statistical analysis. Data was analysed using IBM SPSS Statistics version 23.0 (IBM Corp, Armonk, NY, USA). The WSES Sepsis Severity Score was calculated based on the statistical program.

Univariate analysis was performed to compare patients treated at our hospital $(n=100)$ with those treated at 131 centres globally from 53 countries $(n=4,496)$. This included Pearson's chi-square test or Fisher's exact test, as appropriate, for categorical data and Mann-Whitney $U$ test for continuous or ordinal data. Nonparametric statistical methods were used because they compare ranks and not crude numbers. These should be used when the distribution of data is not normal, the sample size is small or the variance of the groups is not equal.

Finally, the WSES Sepsis Severity Scores and hospital location (i.e. Al-Ain or others) were entered into a direct logistic regression model to ascertain whether treatment at our hospital had an effect on the mortality of patients. A p-value $\leq 0.05$ was considered to be statistically significant.

\section{RESULTS}

The patients treated for clAls at our hospital were from 17 different countries (Table I). 57 patients were manual workers, 14 were office employees/teachers, four were students, 17 were unemployed and eight had an unknown profession. The median
Table I. Countries of origin of Al-Ain Hospital patients with complicated intra-abdominal infections $(n=100)$.

\begin{tabular}{|ll|}
\hline Country & No. (\%) \\
\hline Bangladesh & $21(21.0)$ \\
\hline Pakistan & $13(13.0)$ \\
\hline United Arab Emirates & $13(13.0)$ \\
\hline Egypt & $10(10.0)$ \\
\hline Syria & $8(8.0)$ \\
\hline India & $7(7.0)$ \\
\hline The Philippines & $7(7.0)$ \\
\hline Jordan & $4(4.0)$ \\
\hline Morocco & $3(3.0)$ \\
\hline Oman & $3(3.0)$ \\
\hline Sudan & $3(3.0)$ \\
\hline Indonesia & $2(2.0)$ \\
\hline Tunisia & $2(2.0)$ \\
\hline Australia & $1(1.0)$ \\
\hline Ethiopia & $1(1.0)$ \\
\hline Germany & $1(1.0)$ \\
\hline Yemen & $1(1.0)$ \\
\hline
\end{tabular}

age of our patients with clAls was 32 (range 18-75) years, with $75(75.0 \%)$ men and 25 (25.0\%) women (Table II). 6 (6.0\%) patients had healthcare-associated infections and $37(37.0 \%)$ patients had generalised peritonitis. Only $2(2.0 \%)$ patients had malignancy, 2 (2.0\%) patients had serious cardiovascular disease and none were immunosuppressed. 7 (7.0\%) patients were not insured; all were from the Indian subcontinent (of Bangladeshi, Indian and Pakistani nationalities), except for one patient who was an Egyptian tourist.

The most common sources of intra-abdominal infections in our setting were acute appendicitis (61.0\%) followed by perforated duodenal ulcers $(20.0 \%)$. When compared with the global data, our patients were significantly more likely to be male $(p<0.0001)$, were significantly younger $(p<0.0001)$, had a higher incidence of appendicitis and perforated peptic ulcers ( $p<0.0001)$, and had less malignancy $(p=0.001)$, immunosuppression $(p<0.0001)$, serious cardiovascular disease $(p=0.001)$ and healthcare-associated infections ( $p=0.046)$. However, the rate of generalised/diffuse peritonitis was similar to that in the global data $(p=0.83)$.

Table III shows the severity markers and management of our patients. When compared with the global data, our patients had significantly less severe sepsis and septic shock $(p<0.005)$, lower WSES Sepsis Severity Score $(p<0.0001)$ and more delays in surgical intervention $(p=0.001)$. Nevertheless, we had significantly higher application of empirical antimicrobial therapy $(p=0.03)$, and comparable adequate source control $(p=0.54)$ and surgical reinterventions $(p=0.63)$, including relaparotomies. Overall, we had significantly shorter median hospital stays (4 [range 1-52] days vs. 7 [range 1-164] days; $p<0.0001$ ) and a lower mortality rate $(1.0 \%$ vs. $9.3 \% ; p=0.001)$ compared to the global data.

To ascertain whether the hospital setting influenced mortality among patients with clAls, the effect of both the WSES Sepsis 
Table II. Comparison of demographics of Al-Ain Hospital patients with global data.*

\begin{tabular}{|c|c|c|c|}
\hline \multirow[t]{2}{*}{ Variable } & \multicolumn{2}{|c|}{ No. (\%)/median (range) } & \multirow[t]{2}{*}{ p-value $^{\dagger}$} \\
\hline & Al-Ain Hospital $(n=100)$ & Global data $(n=4,496)$ & \\
\hline Age (yr) & $32(18-75)$ & $51(18-99)$ & $<0.0001$ \\
\hline Gender & & & $<0.0001$ \\
\hline Male & $75(75.0)$ & $2,569(57.1)$ & \\
\hline Female & $25(25.0)$ & $1,927(42.9)$ & \\
\hline Source of infection & & & $<0.0001$ \\
\hline Appendicitis & $61(61.0)$ & $1,534(34.1)$ & \\
\hline Cholecystitis & $2(2.0)$ & $837(18.6)$ & \\
\hline Gastroduodenal perforation & $20(20.0)$ & $485(10.8)$ & \\
\hline Postoperative & $3(3.0)$ & $385(8.6)$ & \\
\hline Colonic non-diverticular perforation & $3(3.0)$ & $268(6.0)$ & \\
\hline Small bowel perforation & $1(1.0)$ & $242(5.4)$ & \\
\hline Diverticulitis & $3(3.0)$ & $234(5.2)$ & \\
\hline Post-traumatic & $3(3.0)$ & $114(2.5)$ & \\
\hline Pelvic inflammatory disease & $0(0)$ & $50(1.1)$ & \\
\hline Other & $4(4.0)$ & $347(7.7)$ & \\
\hline Diffuse peritonitis & $37(37.0)$ & $1,611(35.8)$ & 0.83 \\
\hline Healthcare-associated infection & $6(6.0)$ & $564(12.5)$ & 0.046 \\
\hline Immunosuppression & $0(0)$ & $412(9.2)$ & $<0.0001$ \\
\hline Malignancy & $2(2.0)$ & $560(12.5)$ & 0.001 \\
\hline Serious cardiovascular disease & $2(2.0)$ & $782(17.4)$ & 0.001 \\
\hline
\end{tabular}

*From 131 centres globally. †p-value was calculated using Fisher's exact test, Pearson's chi-square test or Mann-Whitney U test.

Table III. Comparison of severity markers and management of patients at Al-Ain Hospital with global data.*

\begin{tabular}{|c|c|c|c|}
\hline \multirow[t]{2}{*}{ Variable } & \multicolumn{2}{|c|}{ No. (\%)/median (range) } & \multirow[t]{2}{*}{ p-value ${ }^{\dagger}$} \\
\hline & Al-Ain Hospital $(n=100)$ & Global data $(n=4,496)$ & \\
\hline Sepsis status on admission & & & $<0.005$ \\
\hline No sepsis & $41(41.0)$ & $1,919(42.7)$ & \\
\hline Sepsis & $53(53.0)$ & $1,788(39.8)$ & \\
\hline Severe sepsis & $5(5.0)$ & $560(12.5)$ & \\
\hline Septic shock & $1(1.0)$ & $229(5.1)$ & \\
\hline WSES Sepsis Severity Score on admission ${ }^{\ddagger}$ & $3(0-11)$ & $3(0-17)$ & $<0.0001$ \\
\hline $0-3$ & $88(88.0)$ & $2,907(64.7)$ & \\
\hline $4-6$ & $10(10.0)$ & $829(18.5)$ & \\
\hline$\geq 7$ & $2(2.0)$ & $750(16.7)$ & \\
\hline Empirical antimicrobial therapy & $100(100)$ & $4,317(96.0)$ & 0.03 \\
\hline Delay in initial intervention (> $24 \mathrm{hr}$ ) & $69(69.0)$ & $2,336(52.0)$ & 0.001 \\
\hline Adequate source control & $92(92.0)$ & $3,825^{\varsigma}(93.4)$ & 0.54 \\
\hline Reintervention & $9(9.0)$ & $493(11.0)$ & 0.63 \\
\hline Hospital stay (day) & $4(1-52)$ & $7(1-164)$ & $<0.0001$ \\
\hline Mortality & $1(1.0)$ & $416(9.3)$ & 0.001 \\
\hline
\end{tabular}

*From 131 centres globally. †p-value was calculated using Fisher's exact test, Pearson's chi-square test or Mann-Whitney $U$ test. ¥Missing data for 10 patients from the global data. §Missing data for 400 patients. WSES: World Society of Emergency Surgery

Severity Score and our hospital setting on mortality was tested using a direct logistic regression model (Table IV). The model was highly significant $\left(p<0.0001\right.$, Nagelkerke's $\left.R^{2}=0.5\right)$. The odds of death increased by 0.78 upon an increase of 1 on the WSES Sepsis Severity Score, which was highly significant $(p<0.0001)$. Although the odds of death decreased by 0.76 in our hospital compared with the global data, this was not significant $(p=0.18)$, indicating that the decrease in mortality could be explained by the decreased sepsis scores of our patients.

\section{DISCUSSION}

We found that among our patients with clAls, there were significantly more men and younger patients. Our patients also had varied sources of clAls, significantly lower sepsis severity 
Table IV. Direct logistic regression model for predicting the mortality of patients with complicated intra-abdominal infection.

\begin{tabular}{|llllll|}
\hline Variable & B & SE & Wald test & p-value & OR (95\% CI) \\
\hline WSES Sepsis Severity Score & 0.58 & 0.02 & 647.4 & $<0.0001$ & $1.78(1.70-1.86)$ \\
\hline Al-Ain Hospital* & -1.44 & 1.09 & 1.77 & 0.18 & $0.24(0.03-1.98)$ \\
\hline Constant & -4.21 & 1.11 & 14.46 & $<0.0001$ & 0.02 \\
\hline
\end{tabular}

${ }^{*}$ Compared with other 131 global centres. B: coefficient; Cl: confidence interval; OR: odds ratio; SE: standard error; WSES: World Society of Emergency Surgery

scores and more delays in surgical intervention when compared with the global data. Overall, we had significantly lower death rates. However, the lower mortality rate seen in our patients was explained by their lower WSES Sepsis Severity Scores rather than our hospital's setting when compared with other hospitals.

Following the discovery of oil in the UAE and its associated fast economic growth, the country's population dynamics have been greatly influenced by the influx of large numbers of expatriate workers who were attracted by its numerous employment opportunities. Workers in the UAE originate from over 200 countries $^{(10)}$ and are of various ethnic backgrounds. This sociocultural diversity and mix not only offers a unique experience but also poses distinctive challenges vis-à-vis the provision of healthcare services. ${ }^{(9)}$ The population is mainly young, with a male-female ratio of approximately $2: 1$ owing to the large influx of young foreign men. ${ }^{(9)}$ This was also reflected in the demographics of our patients with clAls, as we had more men than women and a younger patient population. Patients in the present study were from 17 different countries; $57.0 \%$ of them were manual workers and $87.0 \%$ were expatriates.

The source of infection was significantly different in our patients when compared to the global data, with more appendicitis and perforated duodenal ulcer in our setting. It was interesting to note the high percentage of perforated duodenal ulcers in our population. We have previously documented the higher incidence of perforated duodenal ulcers in Bangladeshi men, particularly during the fasting month of Ramadan. ${ }^{(15}$ Timely and adequate management of clAls usually achieves good results. ${ }^{(2)}$ However, proper source control and appropriate antibiotic therapy are essential for favourable outcome of clAls. If these were not performed early and properly, high morbidity and mortality would be expected among these patients. Although there was delayed management among our patients, we were surprised to find that this was not related to a lack of health insurance - only $7.0 \%$ of patients lacked insurance in our cohort. We have noticed that in our clinical practice, individuals of certain nationalities have a higher tolerance for pain and only present when the pain persists, often reaching a stage of advanced complicated infection by the time of hospital presentation. The management of clAls at our hospital was similar to that in other parts of the world, with proper source control, appropriate use of antibiotics and reinterventions being performed, as necessary. Interestingly, our patients' compliance with empirical antimicrobial therapy was extremely high $(100.0 \%)$. We attribute this high level of compliance to the high quality standards necessitated by the Joint Commission International for accreditation purposes. Our hospital has been accredited by the Commission since 2010.
Clinical trials on patients with severe intra-abdominal infections may not be representative of the true mortality of such conditions. These studies usually indicate an increased survival rate due to the restriction criteria involved. ${ }^{(16,17)}$ It is important to highlight that our study validates the generalisability of the WSES Sepsis Severity Score, as it was conducted on a heterogeneous multiethnic population from an urban general hospital. Although the global data had an overall mortality of $9.3 \%$ and our study had an overall mortality of $1.0 \%$, we found on logistic regression analysis that our local setting did not affect patient mortality. Our study population comprised mainly young, healthy working men, and perforated appendicitis and perforated peptic ulcer were the main pathologies. It was not surprising that the clinical outcome was good for our patients. Patient outcome and mortality were accurately predicted by the WSES Sepsis Severity Score for our patients, further supporting its generalisability and validity.

There were certain limitations to our study. First, data was obtained from a single hospital and the findings may not be generalisable to other hospitals in the country. Second, our hospital is a general hospital and does not have an oncology or transplantation centre, which explains the low incidence of malignancy and immunosuppression observed among our patients. Third, as the number of compared groups was not equal, the variance was expected to be different. As parametric statistical methods are not advisable for such cohorts, we used nonparametric statistical methods that could address this limitation.

In conclusion, although the demographics of our patients and the setting of our hospital significantly differed from those of other international hospitals, the WSES Sepsis Severity Score was very accurate in predicting mortality among our patients with clAIs. This supports the generalisability of the WSES Sepsis Severity Score.

\section{ACKNOWLEDGEMENTS}

The authors thank the WSES for granting permission to use crude data from their database for this study.

\section{REFERENCES}

1. Sartelli M, Viale P, Catena F, et al. 2013 WSES guidelines for management of intra-abdominal infections. World J Emerg Surg 2013; 8:3.

2. Mazuski JE, Solomkin JS. Intra-abdominal infections. Surg Clin North Am 2009; 89:421-37.

3. Pacelli F, Doglietto GB, Alfieri $S$, et al. Prognosis in intra-abdominal infections Multivariate analysis on 604 patients. Arch Surg 1996; 131:641-5

4. Koperna T, Schulz F. Prognosis and treatment of peritonitis. Do we need new scoring systems? Arch Surg 1996; 131:180-6.

5. Mulari K, Leppäniemi A. Severe secondary peritonitis following gastrointestinal tract perforation. Scand J Surg 2004; 93:204-8.

6. Sartelli M, Catena F, Ansaloni L, et al. Complicated intra-abdominal infections in a worldwide context: an observational prospective study (CIAOW Study). World J Emerg Surg 2013; 8:1. 
7. Sartelli M, Catena F, Ansaloni L, et al. Complicated intra-abdominal infections worldwide: the definitive data of the CIAOW Study. World J Emerg Surg 2014; 9:37.

8. Sartelli M, Abu-Zidan FM, Catena F, et al. Global validation of the WSES Sepsis Severity Score for patients with complicated intra-abdominal infections: a prospective multicentre study (WISS Study). World J Emerg Surg 2015; 10:61.

9. Grivna M, Aw TC, El-Sadig M, et al. The legal framework and initiatives for promoting safety in the United Arab Emirates. Int J Inj Contr Saf Promot 2012; 19:278-89.

10. Chaudhry SB. What makes UAE a role model of cohesion. In: Gulf News, 28 May 2016. Available at: https://gulfnews.com/news/uae/society/what-makesuae-a-role-model-of-cohesion-1.1836341. Accessed September 19, 2018.

11. Al Ain Hospital. Available at: https://www.seha.ae/alain/English/aboutus/Pages/ welcome-message.aspx. Accessed September 20, 2018.

12. Inter Press Service News Agency. Abu Dhabi population hits 3 million, fertility rate up to 3.7 per citizen-female. Available at: http://www.ipsnews.net/2017/10/ abu-dhabi-population-hits-3-million-fertility-rate-3-7-per-citizen-female/. Accessed September 19, 2018.

13. Horan TC, Andrus M, Dudeck MA. CDC/NHSN surveillance definition of health care-associated infection and criteria for specific types of infections in the acute care setting. Am J Infect Control 2008; 36:309-32.

14. Dellinger RP, Levy MM, Rhodes A, et al; Surviving Sepsis Campaign Guidelines Committee including The Pediatric Subgroup. Surviving Sepsis Campaign: international guidelines for management of severe sepsis and septic shock, 2012. Intensive Care Med 2013; 39:165-228.

15. Torab FC, Amer M, Abu-Zidan FM, Branicki FJ. Perforated peptic ulcer: different ethnic, climatic and fasting risk factors for morbidity in Al-ain medical district, United Arab Emirates. Asian I Surg 2009; 32:95-101.

16. Merlino JI, Malangoni MA, Smith CM, Lange RL. Prospective randomized trials affect the outcomes of intraabdominal infection. Ann Surg 2001; 233:859-66.

17. Horiuchi A, Watanabe $\mathrm{Y}$, Doi $\mathrm{T}$, et al. Evaluation of prognostic factors and scoring system in colonic perforation. World J Gastroenterol 2007; 13:3228-31.

\section{APPENDIX}

The WSES Sepsis Severity Score (range 0-18) for patients with clAls.

\begin{tabular}{|ll|}
\hline Risk factor & Score \\
\hline Age $>$ 70 yr & 2 \\
\hline Immunosuppression & 3 \\
\hline Setting of acquisition & 2 \\
\hline$\quad$ Healthcare-associated infection & \\
\hline Clinical condition at admission & 3 \\
\hline Severe sepsis & 5 \\
\hline Septic shock & \\
\hline Origin of clAl & 2 \\
\hline Colonic non-diverticular perforation peritonitis & 2 \\
\hline Diverticular diffuse peritonitis & 2 \\
\hline Postoperative diffuse peritonitis & 3 \\
\hline Small bowel perforation peritonitis \\
\hline Delay in source control & 3 \\
\hline Delayed initial intervention $>24 \mathrm{hr}$ \\
\hline
\end{tabular}

clAl: complicated intra-abdominal infection; WSES: World Society of Emergency Surgery 